\title{
Integrating Evaluation Grid Method and Fuzzy Quality Function Deployment to New Product Development
}

\author{
Xinhui Kang $(\mathbb{D}$, Minggang Yang, Yixiang $\mathrm{Wu}(\mathbb{D}$, and Bingqing $\mathrm{Ni}(\mathbb{D}$ \\ School of Art Design and Media, East China University of Science and Technology, No. 130, Meilong Road, \\ Xuhui District, Shanghai 200237, China \\ Correspondence should be addressed to Xinhui Kang; nbukxh@163.com
}

Received 1 October 2017; Revised 29 March 2018; Accepted 19 April 2018; Published 30 July 2018

Academic Editor: Francesco Ferrise

Copyright (c) 2018 Xinhui Kang et al. This is an open access article distributed under the Creative Commons Attribution License, which permits unrestricted use, distribution, and reproduction in any medium, provided the original work is properly cited.

\begin{abstract}
The success of a new product is usually determined not by whether it includes high-end technology, but by whether it meets consumer expectations, especially key Kansei demands. This article aims to evaluate attractive factors (Kansei words) and convert them to design elements to make products stand out in the global competition. The evaluation grid method (EGM) is an important research method of Miryoku engineering. The method can build qualitative relations among consumers' attractive factors and design elements. The quality function deployment (QFD) is a quantitative method which converts customer requirements into engineering characteristics using the House of Quality Matrix. The QFD together with the concept of fuzziness can objectively measure questionnaires made by experts. Accordingly, this paper proposes a systematic approach that integrates the EGM together with the fuzzy QFD for the development of new products. The fuzzy Kano model combined with the fuzzy analytic hierarchy process (AHP) is developed to determine the priority of the development of attractive factors. This empirical study uses minicars as an example to verify the feasibility and validity of the approach. The results are expected to help designers to increase design efficiency and improve consumer satisfaction of new products.
\end{abstract}

\section{Introduction}

With improvements in modern technologies and sophisticated manufacturing, product life cycles have been shortened. Corporations have to keep developing new products to adapt to rapidly changing market demands and sustain operation in the market. However, most traditional designers tend to make decisions based on previous experience and personal preferences. They usually neglect the voice of customers, not only wasting precious time for designing new products, but also increasing risks. Nijssen and Frambach [1] point out that new product development (NPD) faces a high failure rate, where the success rate is generally not larger than $60 \%$. Accordingly, we must fully understand the customer needs of the target market and continue creating superior value for customers in order to bring new products to the society with required novelty and changes [2].

These days, more attention is paid to products' emotional connotations and aesthetic values rather than functional abilities and prices. It has become increasingly vital to take emotional elements into consideration during NPD, as emotions now play more important role when we interact with products in our daily life [3]. Newman [4] mentions three types of consumer demands for products related to basic function attributes, convenient function attributes, and psychological satisfaction attributes. Consumers expect their psychological needs to be met when they purchase a product. According to Jordan's Hierarchy of User Needs, the meaning of a product first comes from its functionality, then usability, and finally pleasure. This is why users' expectations regarding a product come from practical and emotional needs [5]. Jensen [6] points out that, actually, we search for stories, friendship, care, a lifestyle, and character when we shop; that is, we purchase emotions. Therefore, products benefit from being in line with consumers' emotional needs when it comes to their market shares. Besides, a dominant factor that determines the success of a new product is whether it has a form that suits customers' preferences [7]. The product form contributes to consumers' first impression. It triggers their sense of identification and emotional resonance, which results in their 
purchase decisions. Nagamachi, a Japanese scholar, first suggested taking into account customers' senses and feelings (Kansei) in the 1970s. Further, Kansei engineering was developed as a comprehensive consumer oriented technology for the NPD [8]. Researchers consider five senses and their quantification to study consumers' emotions. Tanoue et al. [9] utilize Kansei engineering to evaluate automotive interior images, especially roominess and oppressiveness. Schütte and Eklund [10] apply Kansei engineering to design rocker switches for work-vehicles. Nagamachi [11] presents and discusses Kansei engineering, thus realizing several new Kansei products so far. Vieira et al. [12] use Kansei engineering for the design of in-vehicle rubber keypads. Miryoku engineering is a part of Kansei engineering since 1998, when the Japan Society of Kansei Engineering (JSKE) was established. It mainly discovers user preferences, which come from product values and charms determined by product attributes [13]. Kansei engineering quantifies human's perception and feeling with the method of engineering and then transforms consumers' feeling into the technology of new products. However, Miryoku engineering discusses the relationship between consumers' abstract reasons for specific products and concrete characteristics with the qualitative way of face-to-face interview. Moreover, the personal hierarchical diagram is formed by laddering. "Miryoku" in Japanese means "the power of attractiveness." Product attractiveness is primary to consumers. Based on in-depth interviews, Miryoku engineering helps interviewees to take various appealing factors from samples and transfer the product's Kansei attractiveness into its form with the goal to improve customer satisfaction and market reception.

As an important research method of Miryoku engineering, the objective of the evaluation grid method (EGM) is to build a hierarchical structure between abstract reasons and concrete design elements, which is usually hard to capture. The EGM has been successfully applied to product design, game development, festival industries, and other research fields [14-20]. Nevertheless, there are two urgent issues that need to be solved. First, the screening of words among obtained upper-level attractive factors (Kansei words) is based on their number of appearance by respondents, where frequencies only show the degrees to which words are related to the product but do not reflect their importance. Second, numerical relationships between upper-level attractive factors and lower-level design elements are usually based on multiple linear regressions, such as the Quantification Theory Type I (QT-I) used for mapping, but Kansei data does not always have linear features assumed when using the normal distribution [21]. A linear regression can lead to deviation and misjudgment in the consequent design process.

In the view of the above arguments, the present study intends to import the attractive factors of the EGM into the fuzzy quality function deployment (QFD) system to acquire the best combination of crucial Kansei needs and design elements. First, we adopt the hierarchical diagram obtained by the EGM to the House of Quality (HoQ) and, second, we obtain the crucial attractive factors by combining the two-dimensional fuzzy Kano model and the fuzzy analytic hierarchy process (AHP). Design teams are recommended to gather limited resources and pay attention to these results in order to maximize overall customer satisfaction. They can excavate the most important design elements by comparing crucial attractive factors and design elements obtained by the HoQ. This study aims to discover customers' feelings and translate them into form elements that enhance positive effects and increase the attraction of product appearance. The proposed method is based on the fuzzy theory, used for uncertain consumer requirements (CRs). We build an objective semantic questionnaire to learn real customer Kansei demands to cut losses resulting from colloquial phrases. Furthermore, a brief comparison of the distinction between this study and previous studies has been presented in Table 1. The main contribution of this work can be summarized as follows:

(i) A hybrid framework is proposed to effectively convert the voice of customers (attractive factors) into the voice of engineers (design elements), thus reducing the generation gap between both sides.

(ii) Via combination of a two-dimensional model and the weight analysis method, consumers' attractive factors to target products can be evaluated more accurately.

(iii) Our survey data assist enterprises to identify customers' expectations, thus finally integrating these into the NPD.

The remainder of this article is organized as follows: Section 2 provides a brief literature review. In Section 3, the newly proposed method is explained in detail. In Section 4, a case study for minicars is provided to demonstrate the effectiveness of the developed approach. The paper is concluded in Section 5.

\section{Literature Review}

2.1. Miryoku Engineering and Evaluation Grid Method. Miryoku engineering, proposed by a Japanese scholar Masato Ujigawa and his group in 1991, aims to create attractive products and spaces by adopting a design philosophy centered at consumer preferences [13]. The charm traits of a product can be captured through learning the way in which consumers choose products and studying successful examples of product design, so that an attractive design can be created [22]. However, Miryoku is a vague concept that cannot be measured by specific tools. For this reason, in this research we analyze customers' attractive factors by layers with the aid of the EGM.

The EGM is an important research approach of Miryoku engineering proposed by Japanese scholars Junichiro Sanui and Masao Inui based on the psychologist's Repertory Grid Method of Kelly in 1986 [23] with two added steps (Figure 1). One step compares and evaluates samples in terms of merits and demerits during interviews to obtain original evaluation items through interviewees' perspectives and senses. The other step obtains abstract reasons (upper-level), which connect users' emotion attitudes and product concrete conditions (lower-level). By doing this repeatedly, we can obtain a hierarchical diagram of consumers' inner feelings towards samples [24]. 


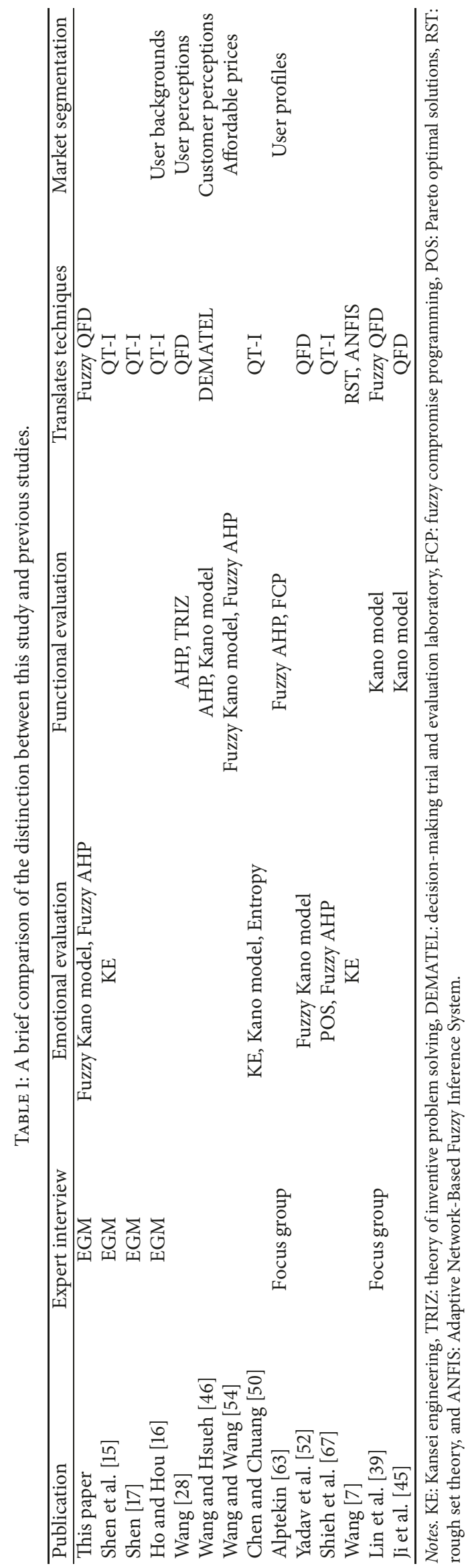




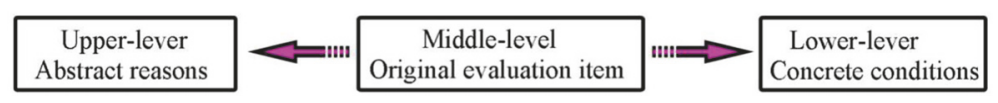

FIGURE 1: A three-level hierarchical diagram for a single evaluation project.

The EGM have been applied to a large number of fields, such as user experience, interior design, cultural and creative industries, and product design. For instance, Park et al. [14] study key user requirements in mobile hospital applications by using the EGM and discuss how to assess and improve user design in mobile and wireless environments. Shen et al. [15] use the EGM for expert evaluation to explore the appeal of the Crossover B-Car interior from the perspectives of usability and functionality. Ho and Hou [16] utilize Miryoku engineering methods combined with a Kansei interface model to examine the relationship between attractive icons and users, where the EGM is used to evaluate icons, and the QT-I is used to analyze the influence of design elements in icons. Shen [17] explores the sociocultural appeal of social networking service (SNS) game content. Chen et al. [18] apply the EGM and QT-I to explore the appeal of Facebook SNS games from the perspectives of game usability and functionality facilitated by the Internet. Using the Taiwan Lantern Festival as a sample, Ma and Tseng [19] adopt the EGM and QT-I to systematically analyze the fuzzy perception of human Kansei factors. The authors select attractive factors before weight analysis for the evaluation of the attractiveness of the festival. $3 \mathrm{C}$ products are used as representatives, and the EGM in Miryoku engineering is adopted for constructing the structure of consumers' preferences for new products. Eventually, a design strategy for attractiveness of new products is established [20].

In this study, we obtain customers' emotional preferences to analyze the semantic structure in detail. We use the EGM to collect the attractive factors of minicars for further quantitative research.

2.2. Fuzzy Quality Function Deployment. The concept of the QFD was first introduced by Akao in 1966. It is a structured methodology used to discuss CRs on products and services. Besides, it is also a process of transforming CRs into engineering characteristics (ECs) [25]. Cristiano et al. [26] successfully apply QFD to obtain the key factors of new products that meet customer expectations. Kowalska et al. [27] implement QFD for a quality analysis of confectionery products. The development of the QFD has taken place for fifty years, and it has been already widely applied to several academic fields and industries [28-33]. The HoQ (Figure 2) is the core of the QFD, which performs a basic and strategic role in the QFD. Products and services depend on customers' needs during the process when HoQ is applied. The voice of customers is compared to the voice of engineers to build priority. According to Hauser and Clausing [34], the application of the QFD reduces product development time by $50 \%$ and costs by $30 \%$. Accordingly, this study mainly focuses on the collection of customer needs and conversion of them into product design parameters.

In the traditional QFD, the impreciseness of consumers' subjective assessments is usually ignored, since variables are supposed to be crisp values. In order to address this issue, some studies combine the fuzzy set theory and QFD to obtain customers' true thoughts. Khoo and Ho [35] process linguistics and identify variables with symmetrical triangular fuzzy numbers (TFNs) for the QFD system and then apply the "voice of customers" containing ambiguity and multiplicity of meaning to design decisions. Chan and $\mathrm{Wu}$ [36] utilize symmetrical TFNs to capture the vagueness of linguistic assessments in the HoQ process. Wu [37] proposes a fuzzy HoQ model and the QFD for the fuzzy regression estimation problem. Zaim et al. [38] adopt the fuzzy QFD and ANP weighted crisp for product development. Lin et al. [39] introduce an integrative framework of the Kano model into the fuzzy QFD for Taiwanese Ban-Doh banquet culture. Vinodh et al. [40] apply the fuzzy QFD to the sustainable design of consumer electronic products. Following these ideas, this study uses fuzzy numbers to replace crisp values in matrix operations to enhance the reliability of results for objective measurement.

2.3. Two-Dimensional Quality Model. In order to overcome the disadvantages of one-dimensional quality cognition, Kano et al. [41] suggest a two-dimensional model of quality to emphasize the importance of interaction between product quality and overall customer satisfaction from the asymmetric nonlinear point of view. From this we can learn the relationship between products' attributes and customer satisfaction through the classification of attributes. Berger et al. [42] employ the Kano model to understand customer-defined quality. Yadav et al. [43] integrate both Kano and robust design approach for aesthetical car profile design. Velikova et al. [44] apply the Kano model to identify the overall satisfaction of a wine festival. The Kano model has also been widely used in product design, real estate sales, hotel services, and some other fields [45-50].

The traditional Kano survey method, however, merely allows single choices from five standard answers. This prevents people from expressing the diversity of their logical thinking. Moreover, customers' feelings can easily be influenced as the decision-making environment is quite complicated, which leads to wrong classification results. Accordingly, Lee and Huang [51] modify the traditional Kano questionnaire using the fuzzy theory, allowing giving multiple answers to acquire more responsive results. Yadav et al. [52] integrate the fuzzy Kano model and QFD to explore the prioritization of the aesthetic attributes of car profiles and merge customers' aesthetic feelings into the product design process. Taking smart pads as an example, Wang [53] incorporates customer satisfaction into the decision-making process of product configuration from the fuzzy Kano model perspective. Wang and Wang [54] employ the fuzzy Kano model to elicit the customer perceptions of the optional attributes 


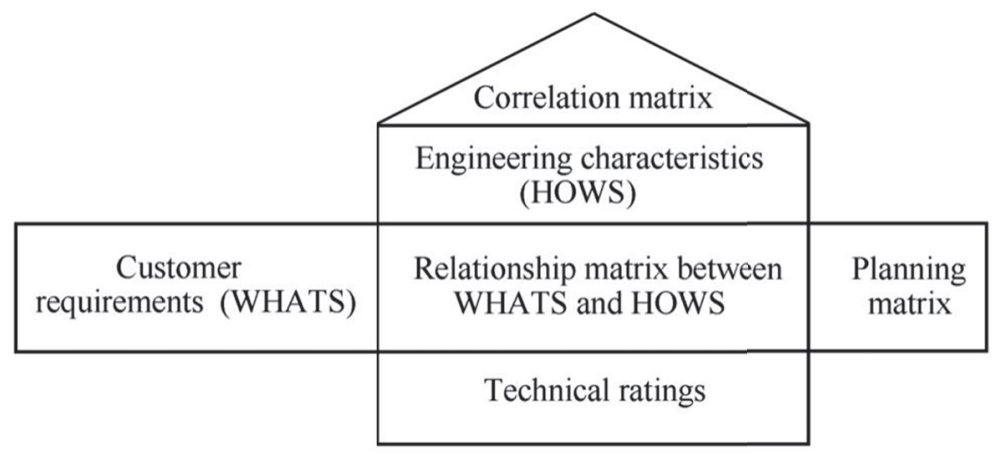

FIGURE 2: The house of quality.

of smart cameras. It is a well-accepted fact from literature that the fuzzy Kano model enables more elastic responses to questionnaires on the semantic scale to make them more convenient for interviewees to show multiple feelings, which not only can assist in knowing customers' inner feelings but can also help to shorten the NPD period. Unfortunately, the fuzzy Kano model cannot prioritize attributes within the same category and can have difficulty in accurate classification of CRs when there is only small statistical difference between two or more categories [55]. Accordingly, this study supposes that attributes form a multicriteria decision-making problem and uses the weight approach to calculate their raw weights and then adjust the weights in accordance with the fuzzy Kano model classification to determine priority ratings.

2.4. Fuzzy Analytic Hierarchy Process. The analytic hierarchy process (AHP), a decision-making method developed by Saaty [56] in 1971, is mainly used in cases with uncertainty and decision problems with various evaluation criteria. Zhu et al. [57] present the AHP to calculate the relative weight of each evaluation criterion for design concept alternatives. Sato et al. [58] integrate both the AHP and the marginal analysis approach for build-to-order products. Furthermore, Ooi et al. [59] use the AHP to overcome the ambiguities involved in assessing the relative importance weightings of target properties in multi-objective molecular design problems. Although the AHP is easy to use, experts can be affected by subjective cognitive factors in assessment. The fuzzy set theory, first proposed by Zadeh [60], describes fuzzy phenomena in daily life. This can be thought of as an extension of traditional sets in which each element must either be in the set or not in the set (i.e., 0 or 1). Accordingly, Laarhoven and Pedrycz [61] propose to use TFNs of the fuzzy set theory directly in the pairwise comparison matrix of the AHP in order to overcome experts' difficulty in judgment due to inevitable ambiguous words, the method is called the fuzzy AHP. In the following research, Buckley [62] applies the fuzzy set theory to the traditional AHP and generalizes the notion of consistency in fuzzy matrices. Alptekin [63] provides endusers with a decision support framework based on the fuzzy AHP and fuzzy compromise programming methodologies in order to select optimal digital cameras according to their preferences. Cho and Lee [64] classify the success factors of the commercialization of new products and analyze which factors should be primarily considered by the fuzzy AHP approach. Yeh et al. [65] use the fuzzy AHP and fuzzy decisionmaking trial and evaluation laboratory (FDEMATEL) to identify critical factors in the NPD. Sabaghi et al. [66] employ the fuzzy AHP together with Shannon's entropy formula to determine the relative importance of each element in a fuzzyinference system. Shieh et al. [67] employ the fuzzy AHP to gain optimal car profile design solutions.

The research above has made it clear that the best feature of the fuzzy AHP is the ability to obtain systematically complex relations among assessment criteria with a hierarchical structure, which leads to excellent results in the evaluation of design processes and emotional dimensions. Accordingly, this study uses the fuzzy AHP to establish a hierarchical structure of the attractive factors of minicars and integrates interviewees' individual opinions to obtain the priority weights of criteria.

\section{The Proposed Integrative Method}

As shown in Figure 3, this study proposes a systematic method of creating attractive new products, using the EGM combined with the fuzzy QFD to obtain accurately relationships between consumers' visual appeals and specific product form elements. The experiment can be divided into three stages as follows:

(i) First, we conduct in-depth interviews with highly involved groups using the EGM, analyze products' attractive factors, extract upper-level abstract reasons, middle-level original evaluation items and low-level concrete conditions, and obtain the corresponding three-level evaluation structure diagram. Then, we import the hierarchical diagram to the HoQ, with the upper attractive factors at the left side of the CRs facet, and the original items and concrete conditions at the top of the HoQ.

(ii) Second, at the left side of the HoQ, we divide attractive factors according to quality attributes using the fuzzy Kano model to determine attractive attributes, onedimensional attributes, and must-be attributes that have remarkable influence on customer satisfaction 


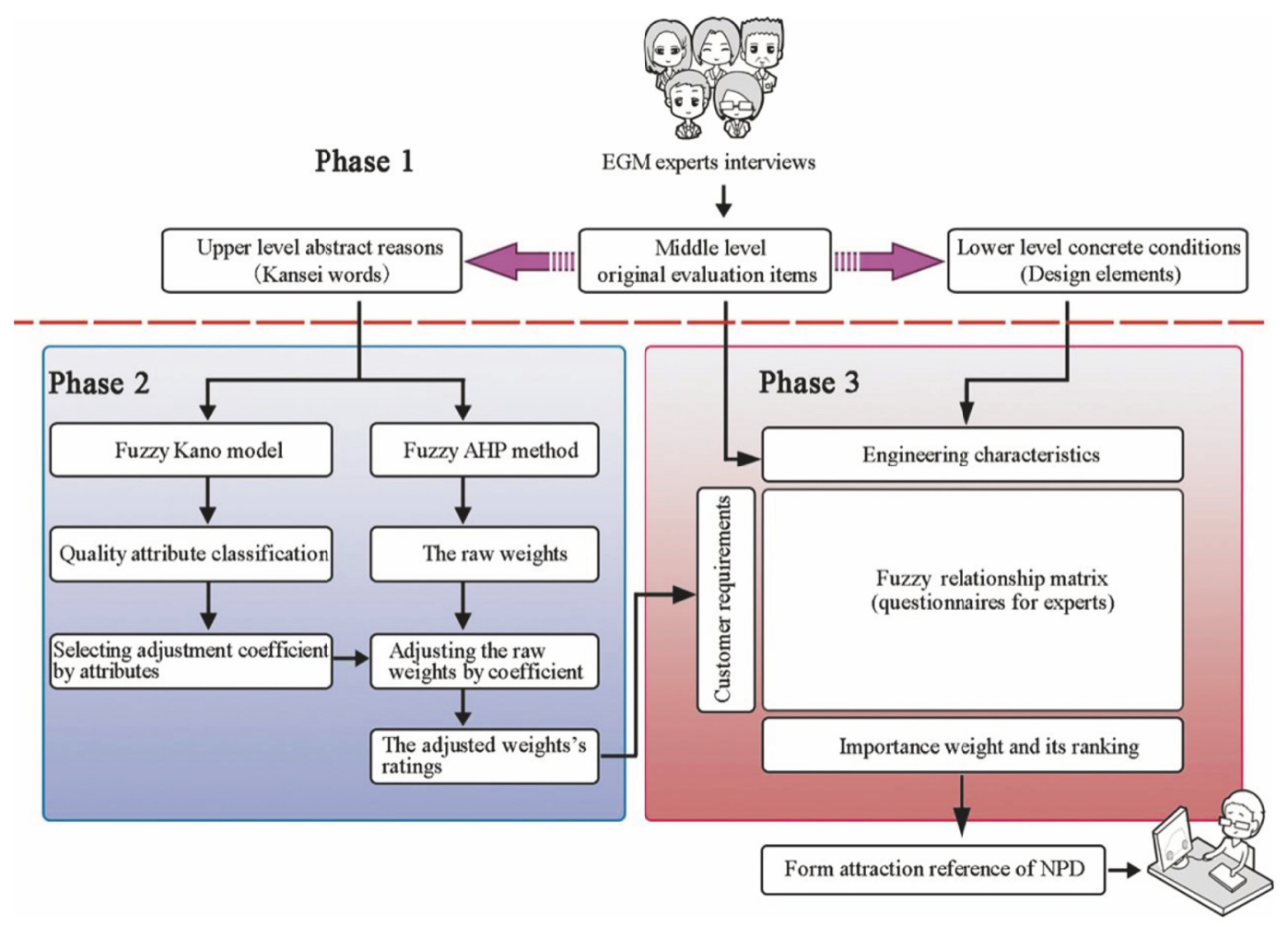

FIGURE 3: The proposed integrative method.

and analyze customers' true needs therefrom. Then, after calculating the raw weights of factors, the fuzzy AHP is used to adjust the weights in accordance with the results on attribute determination, where the final decision regarding what key factors to be given priority in development is made.

(iii) Finally, by sorting the obtained weights, the attractive factors are translated into design elements to meet customer needs after comparing them using the HoQ matrix.

3.1. Phase One: Assessing the Attractive Factors of the Products. At this stage, we commit to the product domain and collect experimental samples. After that the participants make comments regarding sample preferences and learn their original evaluation items in the domain. We then guide them to talk about abstract feelings and concrete conditions by providing additional questions. Finally, we draw an overall evaluation hierarchical diagram. Experimental results can be obtained through direct qualitative reference or quantitative analysis, to grasp clearly the real opinion of customers. follows:

The procedure of the EGM can be briefly described as

(1) Prepare relevant questions and pictures needed for the interview.

(2) Conduct one-to-one interviews and ask every interviewee to divide the pictures into two groups, those they like and dislike.
(3) Remove the ones they dislike.

(4) Let the interviewees provide reasons for their preferences in order to build their original evaluation items.

(5) Ask them about abstract reasons (upper-level) and details (lower-level) they like in the light of the original evaluation items.

(6) Gather all notes from the interviews and connect all corresponding items using straight lines to show hierarchical relations.

(7) Due to the excessive Kansei words at the upper-level, we group the ones with similar contents and attributes using the KJ method, name such groups, and repeat this step until no groups can be created any more. After this process, the attractive factors are obtained.

3.2. Phase Two: Determining the Crucial Attractive Factors. The Kano attribute classification is conventionally undertaken by using a number of bidirectional questions to differ attributes using cross-pairs [68]. The questions on both sides are opposite statements. One of these can be "when attributes are sufficient, what about customer satisfaction?" and the other "when attributes are insufficient, what about customer satisfaction?" The answer options include "dissatisfied," "live with it," "indifferent," "must-be", and "satisfied." Ultimately, we can determine the product attributes through the 25 combinations in the evaluation table (Table 2). They are "attractive," "one-dimensional," "must-be," "indifferent," "reverse," and "questionable." 
TABLE 2: Kano evaluation table.

\begin{tabular}{|c|c|c|c|c|c|c|}
\hline \multirow{2}{*}{\multicolumn{2}{|c|}{ Criteria/attributes }} & \multicolumn{5}{|c|}{ Insufficiency } \\
\hline & & Satisfied & It must be that way & It is Indifferent & I can live with it & Dissatisfied \\
\hline \multirow{5}{*}{ Sufficiency } & Satisfied & Q & $\mathrm{A}$ & $\mathrm{A}$ & $\mathrm{A}$ & $\mathrm{O}$ \\
\hline & It must be that way & $\mathrm{R}$ & I & I & I & M \\
\hline & It is Indifferent & $\mathrm{R}$ & I & I & I & M \\
\hline & I can live with it & $\mathrm{R}$ & I & I & I & M \\
\hline & Dissatisfied & $\mathrm{R}$ & $\mathrm{R}$ & $\mathrm{R}$ & $\mathrm{R}$ & Q \\
\hline
\end{tabular}

Notes. A: attractive, O: one-dimensional, M: must-be, I: indifference, R: reversal, and Q: questionable.

TABLE 3: TFNs in fuzzy AHP.

\begin{tabular}{lr}
\hline Linguistic Scale & Fuzzy Number \\
\hline Equally important & $\widetilde{1}=(1,1,2)$ \\
Slightly important & $\widetilde{3}=(2,3,4)$ \\
important & $\widetilde{5}=(4,5,6)$ \\
Very important & $\widetilde{7}=(6,7,8)$ \\
Extremely important & $\widetilde{9}=(8,9,9)$ \\
Intermediate Value inserted between two continuous dimensions & $\widetilde{2}=(1,2,3) ; \widetilde{4}=(3,4,5) ; \widetilde{6}=(5,6,7) ; \widetilde{8}=(7,8,9)$ \\
\hline
\end{tabular}

However, multiple choices are allowed in the fuzzy Kano model. According to the fuzzy feelings of interviewees, we can bidirectionally assign a percentage to the corresponding $1^{\text {st }}$ to $3^{\text {rd }}$ answers, with 1 being their total sum. For instance, the answers "sufficiency" and "insufficiency" to a product's attractive factor can be described as suf $=(0.7,0.3,0,0,0)$ and $i n s=(0,0,0.1,0.3,0.6)$. We can obtain a $5 \times 5$ fuzzy relation matrix $S$ through matrix multiplication $(s u f)^{t} \otimes(i n s)$. The superscript $t$ denotes the transpose operation:

$$
S=\left[\begin{array}{ccccc}
0 & 0 & 0.07 & 0.21 & 0.42 \\
0 & 0 & 0.03 & 0.09 & 0.18 \\
0 & 0 & 0 & 0 & 0 \\
0 & 0 & 0 & 0 & 0 \\
0 & 0 & 0 & 0 & 0
\end{array}\right]
$$

Based on Table 2's identifying two-dimensional attribute classification in matrix $\mathrm{S}$, we can select something as follows:

$$
T=\left\{\frac{0.28}{A}, \frac{0.18}{M}, \frac{0.42}{O}, \frac{0.12}{I}, \frac{0}{R},\right\}
$$

In order to discover more pleasant classification, we usually use the standard $\alpha$ - cut to obtain $\left\{T_{h}\right\}_{\alpha}$. Let the threshold value be $\alpha \geq 0.4$ as an example. When the attribute membership function is greater than or equal to $\alpha$, this attribute value is " 1 "; otherwise the value is " 0 ." Therefore, the result of the foregoing example is one-dimensional. Different participants may have different feelings towards the degree of the sufficiency of attributes, so the questionnaire takes the individual with the highest frequency. When the final scores are the same and cannot be distinguished, the priority of evaluation is $M>O>A>I$ [69].

In the next stage, the attractive factors are transformed into evaluation criteria and the fuzzy AHP is used to simplify the complex system into a logical hierarchical relationship and integrate the individual opinions of the expert group in order prioritize criteria. Typically, the fuzzy AHP consists of the following six steps:

(1) Build the hierarchical structure of evaluation criteria.

(2) Build the fuzzy judgment matrix $\widetilde{A}$ and compute the weight vector $\widetilde{r}_{i}$.

Based on the questionnaires, we use TFNs (Table 3) to express experts' assessments regarding the relative importance of the criteria. The linguistic scale is represented by the nine-point scale, where "equally important," "slightly important," "important," "very important," and "extremely important" are given the values $\widetilde{1}, \widetilde{3}, \widetilde{5}, \widetilde{7}$, and $\widetilde{9}$, respectively, and the values $\widetilde{2}, \widetilde{4}, \widetilde{6}$, and $\widetilde{8}$ are intermediate (Figure 4 ). The fuzzy pairwise comparison matrix $\widetilde{A}$ is built, and the experts' weight vector $\widetilde{r}_{i}$ towards criteria is obtained as the geometric mean, as shown in

$$
\begin{aligned}
& \widetilde{A}=\left[\begin{array}{cccc}
1 & \tilde{a}_{12} & \cdots & \tilde{a}_{1 n} \\
\tilde{a}_{21} & 1 & \cdots & \tilde{a}_{2 n} \\
\vdots & \vdots & \ddots & \vdots \\
\tilde{a}_{n 1} & \tilde{a}_{n 2} & \cdots & 1
\end{array}\right]=\left[\begin{array}{cccc}
1 & \tilde{a}_{12} & \cdots & \tilde{a}_{1 n} \\
\frac{1}{\widetilde{a}_{12}} & 1 & \cdots & \tilde{a}_{2 n} \\
\vdots & \vdots & \ddots & \vdots \\
\frac{1}{\tilde{a}_{1 n}} & \frac{1}{\tilde{a}_{2 n}} & \cdots & 1
\end{array}\right] \\
& \tilde{r}_{i}=\left(\prod_{j=1}^{n} a_{i j}\right)^{1 / n}=\left[\widetilde{a}_{i 1} \otimes \cdots \otimes \tilde{a}_{i n}\right]^{1 / n}
\end{aligned}
$$

According to the characteristics of TFNs and the extension theorem, for two triangular fuzzy numbers $\widetilde{M}_{1}=$ $\left(l_{1}, m_{1}, u_{1}\right)$ and $\widetilde{M}_{2}=\left(l_{2}, m_{2}, u_{2}\right)$, the operations are as follows $[70,71]$ : 


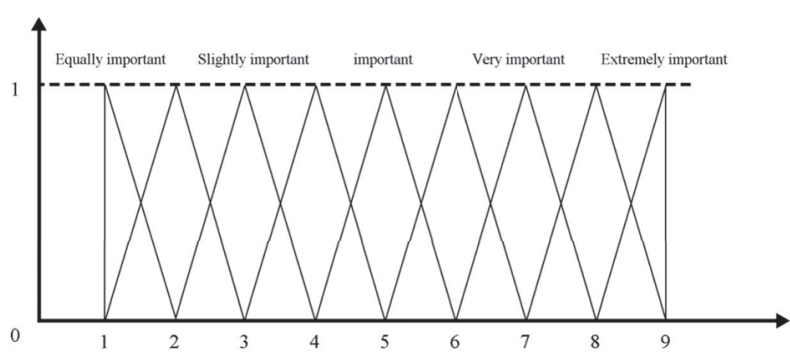

FIgURE 4: Linguistic scale in fuzzy AHP.

Addition $\oplus$

$$
\begin{aligned}
\widetilde{M}_{1} \oplus \widetilde{M}_{2} & =\left(l_{1}, m_{1}, u_{1}\right) \oplus\left(l_{2}, m_{2}, u_{2}\right) \\
& =\left(l_{1}+l_{2}, m_{1}+m_{2}, u_{1}+u_{2}\right)
\end{aligned}
$$

Multiplication $\otimes$

$$
\begin{aligned}
\widetilde{M}_{1} \otimes \widetilde{M}_{2} & =\left(l_{1}, m_{1}, u_{1}\right) \otimes\left(l_{2}, m_{2}, u_{2}\right) \\
& =\left(l_{1} \otimes l_{2}, m_{1} \otimes m_{2}, u_{1} \otimes u_{2}\right)
\end{aligned}
$$

Defuzzification

$$
\operatorname{Defuzzy}\left(\widetilde{M}_{1}\right)=\frac{\left|\left(u_{1}-l_{1}\right)+\left(m_{1}-l_{1}\right)\right|}{3}+l_{1}
$$
$\widetilde{A}$.

(3) Examine the consistency of the fuzzy judgment matrix

According to the research of Buckley [55], we have the following results:

Suppose $A=\left[a_{i j}\right]$ is a positive reciprocal matrix; then $\widetilde{A}=\left[\widetilde{a}_{i j}\right]$ is a fuzzy positive reciprocal matrix, and if $A=\left[a_{i j}\right]$ is consistent, then $\widetilde{A}=\left[\widetilde{a}_{i j}\right]$ is also consistent. Using this, we know whether the questionnaire is effective. The consistent indexes (CI) and consistent ratios of the pairwise comparison matrices can be calculated as follows:

$$
\begin{aligned}
C I & =\frac{\left(\lambda_{\max }-n\right)}{(n-1)} \\
C R & =\frac{C I}{R I}
\end{aligned}
$$

Here, $\lambda_{\max }$ is the maximum eigenvalue of the pairwise comparison matrix. $\mathrm{n}$ is the number of criteria. RI is the random index (Table 4). The closer the CI to 0 , the higher the consistency. When $C I \prec 0.10$ we assume that the result has passed the consistency test and can be included in the overall judgment value.

(4) Compute the fuzzy weight $\widetilde{w}_{i}$ by normalization

$$
\widetilde{w}_{i}=\widetilde{r}_{i} \otimes\left(\widetilde{r}_{i} \oplus \cdots \oplus \widetilde{r}_{m}\right)^{-1}
$$

(5) Defuzzification. Use the center of area method in (7) to defuzzify the TFNs and find out the best nonfuzzy performance value or the best crisp value, to obtain the explicit weight $\widehat{W}_{i}$ for each scheme.

$$
\widehat{W}_{i}=\operatorname{Defuzzy}\left(\widetilde{W}_{i}\right)
$$

(6) Calculate the relative weight $W_{i}$ for each criterion. The relative weight is the normalized value after defuzzification:

$$
W_{i}=\frac{\widehat{W}_{i}}{\sum_{i=1}^{n} \widehat{W}_{i}}
$$

The fuzzy AHP has determined the raw weight values of attractive factors criteria according to the interviewees' knowledge. The procedure of adjusting weights includes understanding customers' quality attributes towards different factors using the fuzzy Kano model questionnaire, the aim of which is to maximize the high return performance criteria. Tan and Pawitra [72] suggest that designers should first pay attention to attractive attributes, then one-dimensional attributes, and at last must-be attributes, before setting the adjustment coefficient $K$ as 4,2 , and 1, respectively. The weight adjustment of the attractive factors can be calculated as follows [50]:

$$
w_{i \_a d j}=\frac{W_{i} K_{i}}{\sum_{i=1}^{n} W_{i} K_{i}}
$$

In the equation, $w_{i_{-} a d j}$ is the weight value adjusted for the $i t h$ element, $W_{i}$ stands for the raw weight of the ith element, $i=1,2, \ldots, n$, and $K_{i}$ is the adjustment coefficient determined by the two-dimensional quality. The priority of attractive factors is determined using the weight adjustment method by combining importance with satisfaction to use CRs analysis at the left side of the HoQ.

3.3. Phase Three: Evaluating the Relationship between Crucial Attractive Factors and Design Elements. During the fuzzy QFD, we first consider the CRs facet, whose weight value is calculated using the fuzzy AHP. Next, we decide the linkage strength of the relationship between WHATS and HOWS. In this study, we assign the impact degree to the relation matrix according to the collection of experts' opinions and mark it as Cohen's [73] relation symbol (see Table 5). If there is no relation, there is no mark. $\triangle$ means weak correlation, $\bigcirc$ means moderate correlation, and $\odot$ means strong correlation. Then, we turn these marks into TFNs. Every ECs has to pair with at least one relation symbol of CRs; otherwise it should be abandoned.

The basic theory of the fuzzy QFD is built on quantitative and qualitative analysis. The absolute value of the ECs of the HoQ, $A I_{j}$, can be obtained using the evaluation method, which is to multiply the CRs weight by the correlation symbol of the correlation matrix and then sum these results. The relative weight $R I_{j}$ is the normalized value of the absolute weight:

$$
\begin{aligned}
& A I_{j}=\sum_{i=1}^{n} W_{i} \otimes R_{i j} \\
& R I_{j}=\frac{A I_{j}}{\sum_{j=1}^{m} A I_{j}}
\end{aligned}
$$


TABLE 4: RI Value.

\begin{tabular}{cccccccccccc}
\hline$n$ & 1 & 2 & 3 & 4 & 5 & 6 & 7 & 8 & 9 & 10 & 11 \\
\hline RI & 0.00 & 0.00 & 0.58 & 0.90 & 1.12 & 1.24 & 1.32 & 1.41 & 1.45 & 1.49 & 1.51 \\
\hline
\end{tabular}

TABLE 5: Relation matrix symbols and TFNs in fuzzy QFD.

\begin{tabular}{lcc}
\hline Symbol & Definition & Fuzzy numbers \\
\hline Blank & No Relationship & $(0,0,0)$ \\
$\triangle$ & Weak Relationship & $(1,3,5)$ \\
$\bigcirc$ & Medium Relationship & $(3,5,7)$ \\
$\bigcirc$ & Strong Relationship & $(5,7,9)$ \\
\hline
\end{tabular}

where $A I_{j}$ is the absolute importance of the $j t h \mathrm{HOW}$, $W_{i}$ is the weight of the ith WHAT, $R_{i j}$ is the degree of the relationship between the ith WHAT and the $j$ th HOW, $i=$ $1,2, \ldots, n, n$ is the total number of CRs, $j=1,2, \ldots, m$, and $m$ is the total number of ECs.

\section{Case Study}

In this section we choose minicars as the study subject. Minicars have become popular due to small dimensions and low fuel consumption. Consumers can get in touch with minicars frequently in daily life, so it is easy for them to get impressed and have deep understanding of the concept, which is good for the survey. Besides, the manufacturing technologies of the automobile industry have become quite mature and the process of purchasing a car by consumers has become more closely related to their considerations at the Kansei level. Therefore, the question of whether the appearance of minicars meets customers' psychological feelings has great influence on consumer desires. In what follows, we apply the proposed method to minicars, although it is also applicable to other product design fields.

4.1. Phase One: Assessing the Attractive Factors of Minicars. 95 minicars from 2012 to 2017 are collected from professional books, magazines, and the Internet as a sample. The sample is presented as 45 degree side photos of $297 \mathrm{~mm} \times 210 \mathrm{~mm}$. The backgrounds and logos of the cars are excluded to reduce interference.

This study is divided into two parts: the EGM qualitative interview and quantitative questionnaire. 10 experts ( 5 males and 5 females) with more than 3 -year driving experience and 5-year design experience act as interviewees in the EGM, fuzzy AHP, and fuzzy QFD. The fuzzy Kano model questionnaire is released through the Internet. 150 interviewees (75 males and 75 females), from 25 to 50 years old, are invited.

After interviewing the participants regarding their feelings towards the pictures and analyzing the features of the EGM, we obtain 33 abstract reasons (upper-level), 10 original evaluation items (middle-level) and 140 concrete conditions (lower-level). Too many abstract reasons prevent consumers from distinguishing styles and images. Accordingly, we use the KJ method to group the factors. 5 experienced designers simplify the 33 words to 7 representative upper-level abstract reasons (Figure 5). Namely, the attractive factors of minicars are "small and cute," "light and lively," "fashionable and tasteful," "appealing and delicate," "noble and elegant," "hard and burly," and "comfortable and ventilate." Figures in brackets represent the numbers of times the descriptions appeared. Taking "fashionable and tasteful" as an example, we draw the corresponding hierarchical structure (Figure 6).

4.2. Phase Two: Determining Crucial Attractive Factors. Consumers' feelings towards products are multiple-criteria characteristics. However, it is truly hard for designers to measure the relationship between performance criteria and customer satisfaction based on their subjective experiences. Therefore, this study uses the fuzzy set theory combined with the Kano model to better identify the 7 quality attributes of minicars.

The study uses a two-side questionnaire to ask interviewees about their satisfaction related to Kansei quality. From the classification results presented in Table 6, "fashionable and tasteful" and "appealing and delicate" are most attractive to consumers when they select minicars. The 4 attributes "small and cute," "light and lively," "hard and burly," and "comfortable and ventilate" are one-dimensional, having a linear relation with customer satisfaction. "Noble and elegant" is a must-be attribute, as the lack of it leads to customers' strong dissatisfaction.

In this research, 7 attractive factors are used as evaluation criteria. According to ((3)-(11)), to calculate the 10 experts' normalized weights $\mathrm{W}$, we take the sum of the criteria relative weights to be $1 . \mathrm{W}_{\mathrm{i}}$ stands for the arithmetic average value of the 10 experts' values, which is shown in Table 7.

Since the importance of a criterion provided by the fuzzy AHP is a one-dimensional concept, it cannot recognize different effects on customer satisfaction. The two-dimensional quality of the fuzzy Kano model helps to understand what customers really need and support designers by providing an important reference on what criteria to develop first. With the help of (12), we obtain the adjusted weights corresponding to raw weights and the attributive classification of the 7 attractive factors, which is shown in Table 8.

4.3. Phase Three: Transforming Design Elements. According to the normalized weight values presented in Table 8, the attractive factor "fashionable and tasteful" ranks the highest. The words in its group are "fashionable," "technological," "modern," "tasteful," "futuristic," and "wise." We obtain their weights and sequence using the fuzzy AHP and then use them in the CRs at the left side of the HoQ, where the corresponding original evaluation item of "fashionable and tasteful" shown in Figure 6 and concrete conditions are imported to the ECs of the HoQ. We determine the strength of the association between the CRs and ECs using matrix notation and map the incidence matrix table (Figure 7), before determining the specific design elements and design focus using ((13)-(14)). 


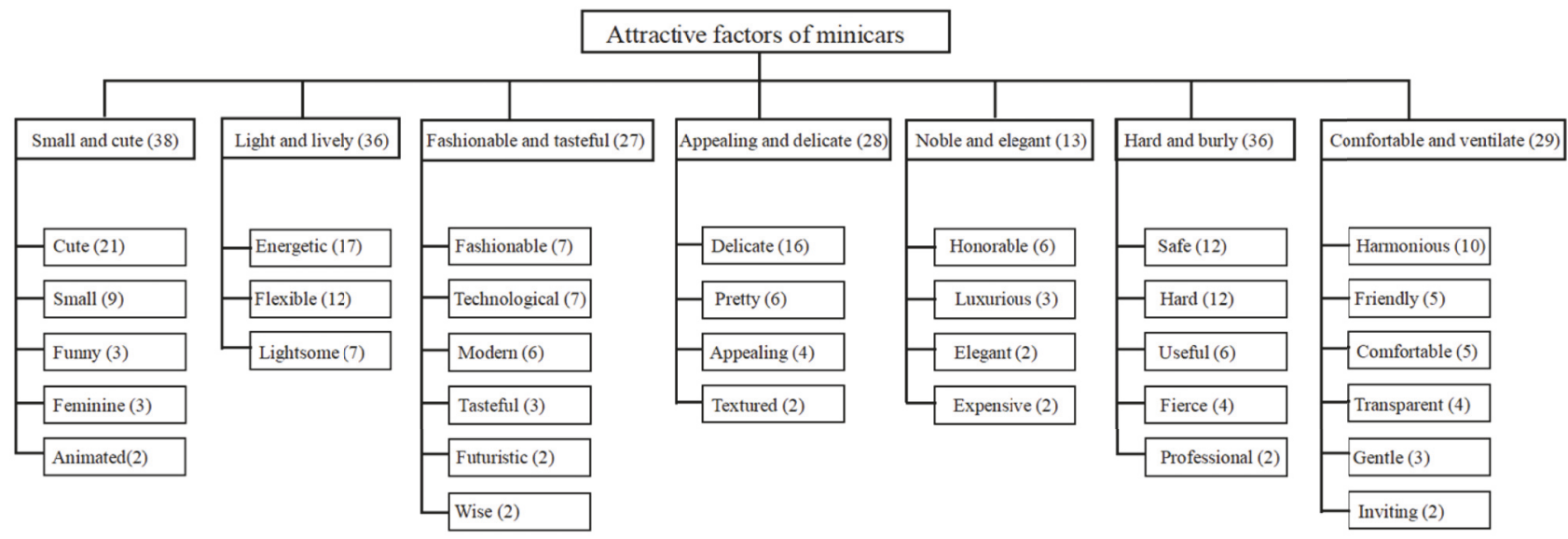

FIGURE 5: Hierarchical structure of minicars' attractive factors.

\section{Abstract}

Upper-level

(Kansei words)
Middle-level

(original evaluation item) concrete

Lower-level

(design elements)

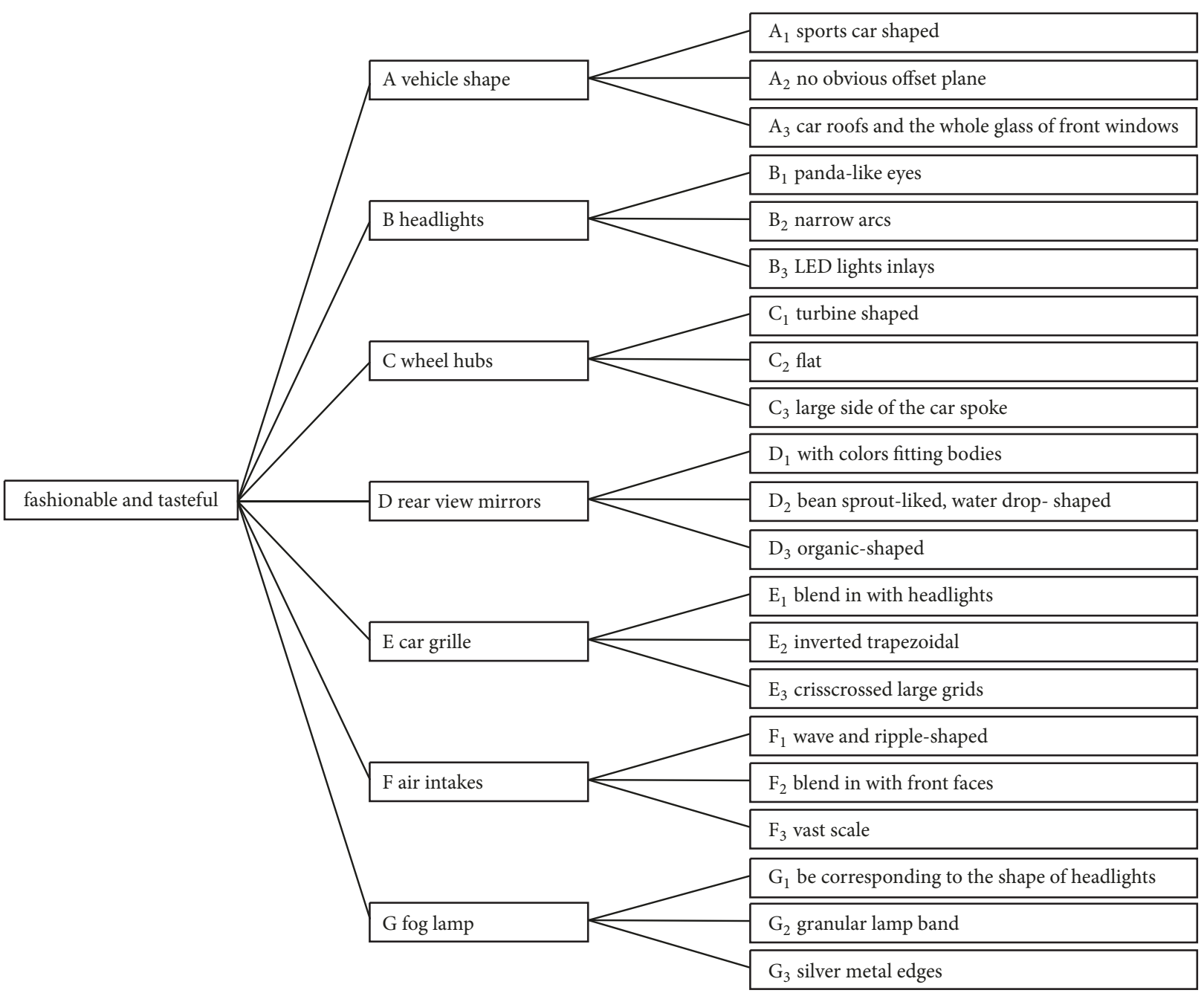

Figure 6: The corresponding hierarchical diagram of "fashionable and tasteful". 
TABLE 6: The fuzzy Kano model classification of abstract attractive factors.

\begin{tabular}{lcccccccc}
\hline Factors & M & O & I & A & R & Q & Total (\%) & Category \\
\hline Small and cute & 17 & 47 & 23 & 10 & 3 & 0 & 100 & O \\
Light and lively & 19 & 31 & 22 & 27 & 1 & 0 & 100 & O \\
Fashionable and tasteful & 6 & 17 & 38 & 39 & 0 & 0 & 100 & A \\
Appealing and delicate & 3 & 15 & 29 & 51 & 2 & 0 & 100 & A \\
Noble and elegant & 43 & 34 & 15 & 8 & 0 & 0 & 100 & O \\
Hard and burly & 28 & 36 & 24 & 12 & 0 & 0 & 0 \\
Comfortable and ventilate & 19 & 55 & 14 & 12 & 0 & 0 & 100 & O \\
\hline
\end{tabular}

Notes. A: attractive, O: one-dimensional, M: must-be, I: indifference, and R: reversal.

TABLE 7: Ten experts' raw weights.

\begin{tabular}{|c|c|c|c|c|c|c|c|c|c|c|c|c|}
\hline Factors & 1 & 2 & 3 & 4 & 5 & 6 & 7 & 8 & 9 & 10 & $\mathrm{~W}_{\mathrm{i}}$ & W \\
\hline Small and cute & 0.018 & 0.097 & 0.042 & 0.090 & 0.025 & 0.019 & 0.032 & 0.020 & 0.019 & 0.335 & 0.070 & 0.070 \\
\hline Light and lively & 0.076 & 0.094 & 0.233 & 0.129 & 0.081 & 0.071 & 0.089 & 0.042 & 0.089 & 0.193 & 0.110 & 0.110 \\
\hline Fashionable and tasteful & 0.419 & 0.054 & 0.058 & 0.065 & 0.409 & 0.267 & 0.242 & 0.115 & 0.195 & 0.118 & 0.194 & 0.194 \\
\hline Appealing and delicate & 0.061 & 0.213 & 0.122 & 0.045 & 0.049 & 0.133 & 0.439 & 0.106 & 0.377 & 0.081 & 0.163 & 0.163 \\
\hline noble and elegant & 0.254 & 0.028 & 0.160 & 0.234 & 0.204 & 0.038 & 0.066 & 0.409 & 0.092 & 0.023 & 0.151 & 0.151 \\
\hline Hard and burly & 0.035 & 0.071 & 0.059 & 0.079 & 0.038 & 0.060 & 0.030 & 0.062 & 0.037 & 0.182 & 0.065 & 0.065 \\
\hline Comfortable and ventilate & 0.137 & 0.443 & 0.327 & 0.359 & 0.195 & 0.413 & 0.102 & 0.246 & 0.193 & 0.068 & 0.248 & 0.248 \\
\hline CI & 0.093 & 0.087 & 0.048 & 0.068 & 0.062 & 0.083 & 0.075 & 0.075 & 0.080 & 0.089 & & \\
\hline
\end{tabular}

TABle 8: Adjusted weights.

\begin{tabular}{|c|c|c|c|c|c|c|}
\hline Factors & Attributes classification & Adjustment coefficient & Weights & Adjusted weights & Normalized weights & Rank \\
\hline Small and cute & $\mathrm{O}$ & 2 & 0.070 & 0.140 & 0.055 & 6 \\
\hline Light and lively & $\mathrm{O}$ & 2 & 0.110 & 0.220 & 0.086 & 4 \\
\hline Fashionable and tasteful & $\mathrm{A}$ & 4 & 0.194 & 0.776 & 0.303 & 1 \\
\hline Appealing and delicate & A & 4 & 0.163 & 0.652 & 0.254 & 2 \\
\hline Noble and elegant & M & 1 & 0.151 & 0.151 & 0.059 & 5 \\
\hline Hard and burly & $\mathrm{O}$ & 2 & 0.065 & 0.130 & 0.051 & 7 \\
\hline Comfortable and ventilate & $\mathrm{O}$ & 2 & 0.248 & 0.496 & 0.193 & 3 \\
\hline
\end{tabular}

4.4. Discussion. In this study, we use the EGM to assess the attractive factors of minicars and use the matrix deployment of the fuzzy QFD to discover the relationship between customers' emotional preferences and minicar' design elements. The numbers of times the 7 attractive factors mentioned by the experts are not the same. "Small and cute" is the most frequently mentioned word (38 times), and "noble and elegant" is the least mentioned one (13 times). We analyze this from the perspective of the traditional Miryoku engineering and draw the conclusion that "small and cute" is what mostly affects consumers' Kansei evaluation, while "noble and elegant" is of the least importance. In other words, we should first focus on the "small and cute" attribute when designing minicars to address customers' emotional demands.

However, we can learn from the statistics of the second stage that the final weight of "small and cute" ranks the sixth. The reason for such difference is that the number of mentions does not always correspond to importance. When consumers choose minicars, they have certain expectations regarding it being small, so naturally "small and cute" is in their mind, while in reality it cannot inspire their purchasing desire.
In addition, "small and cute" has been defined as a onedimensional attribute, as is shown in the quality classification results of the fuzzy Kano model in Table 6. That is to say, quality performance is in direct proportion to customer satisfaction. Nevertheless, "appealing and delicate" with 28 mentions and "fashionable and tasteful" with 27 mentions have been classified as attractive qualities. They can catch customers' attention and are easier to become competitive advantages.

The top 3 attractive factors are "fashionable and tasteful" (30.3\%), "appealing and delicate" (25.4\%), and "comfortable and ventilate" (19.3\%), with the total weight of $75 \%$. This conclusion shows that the 3 factors should be given full attention when designing a minicar. Consumers usually expect that the minicar design matches the trend of the times, reflects personal tastes, and is accompanied by delicate details. At the same time, regardless of how small a minicar is, it also needs to be comfortable and inviting and not depressing visually. The remaining four attractive factors include "light and lively" (8.6\%), "noble and elegant" (5.9\%), "small and cute" (5.5\%), and "hard and burly" (5.1\%), with the total weight value of 


\begin{tabular}{|c|c|c|c|c|c|c|c|c|c|c|c|c|c|c|c|c|c|c|c|c|c|c|c|}
\hline & \multicolumn{3}{|c|}{ A vehicle shape } & \multicolumn{3}{|c|}{ B headlights } & \multicolumn{3}{|c|}{ C wheel hubs } & \multicolumn{3}{|c|}{$\begin{array}{l}\text { D rear view } \\
\text { mirrors }\end{array}$} & \multicolumn{3}{|c|}{ E car grille } & \multicolumn{3}{|c|}{$\mathrm{F}$ air intakes } & \multicolumn{3}{|c|}{$\mathrm{G}$ fog lamp } & & \\
\hline & \multirow[t]{2}{*}{$\mathrm{A}_{1}$} & \multirow[t]{2}{*}{$\mathrm{A}_{2}$} & \multirow[t]{2}{*}{$\mathrm{A}_{3}$} & \multirow[t]{2}{*}{$\mathrm{B}_{1}$} & \multirow[t]{2}{*}{$\mathrm{B}_{2}$} & \multirow[t]{2}{*}{$\mathrm{B}_{3}$} & \multirow[t]{2}{*}{$\mathrm{C}_{1}$} & \multirow[t]{2}{*}{$\mathrm{C}_{2}$} & \multirow[t]{2}{*}{$\mathrm{C}_{3}$} & \multirow[t]{2}{*}{$\mathrm{D}_{1}$} & \multirow[t]{2}{*}{$\mathrm{D}_{2}$} & \multirow[t]{2}{*}{$\mathrm{D}_{3}$} & \multirow[t]{2}{*}{$\mathrm{E}_{1}$} & \multirow[t]{2}{*}{$\mathrm{E}_{2}$} & \multirow[t]{2}{*}{$\mathrm{E}_{3}$} & \multirow[t]{2}{*}{$\mathrm{F}_{1}$} & \multirow[t]{2}{*}{$\mathrm{F}_{2}$} & \multirow[t]{2}{*}{$\mathrm{F}_{3}$} & \multirow[t]{2}{*}{$\mathrm{G}_{1}$} & \multirow[t]{2}{*}{$\mathrm{G}_{2}$} & \multirow[t]{2}{*}{$\mathrm{G}_{3}$} & & \\
\hline CRs & & & & & & & & & & & & & & & & & & & & & & importance & rank \\
\hline fashionable & (-) & & & O & $\triangle$ & & & ๑) & & & & & (-) & & & & & & $\triangle$ & & $\triangle$ & 0.075 & 6 \\
\hline technological & & & O & & & (-) & & & & & 0 & & & & & 0 & & & & (0) & & 0.202 & 2 \\
\hline modern & O & $\triangle$ & (-) & & () & & () & & & $\triangle$ & & O & & O & & (-) & () & $\triangle$ & & & O & 0.173 & 4 \\
\hline tasteful & & O & & & & 0 & & & & (-) & & & 0 & & & & 0 & & & & & 0.205 & 1 \\
\hline futuristic & & & (-) & & & & & O & $\triangle$ & & $\triangle$ & $\triangle$ & & & & & $\triangle$ & & & $\triangle$ & $\triangle$ & 0.165 & 5 \\
\hline wise & $\triangle$ & & & ○) & & $\triangle$ & & & O & & $\triangle$ & & & & O & $\mathrm{O}$ & & O & O & O & & 0.182 & 3 \\
\hline absolute weight & 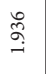 & 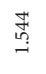 & 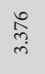 & ફ̆ & ঙ্ণ্ণ & $\begin{array}{l}\text { \&ू } \\
\text { ì }\end{array}$ & $\overrightarrow{\mathrm{I}}$ & 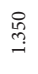 & 笨 & $\stackrel{\sharp}{ٌ}$ & $\begin{array}{l}\vec{n} \\
\text { i }\end{array}$ & 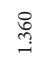 & 号 & 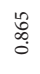 & $\frac{\circ}{\circ}$ & $\stackrel{\vec{m}}{m}$ & $\stackrel{\vec{N}}{\stackrel{i}{i}}$ & ફે & $\stackrel{\leftrightarrow}{\stackrel{m}{=}}$ & $\underset{\infty}{\stackrel{\infty}{i}}$ & $\stackrel{\substack{\infty \\
\hdashline}}{\rightarrow \rightarrow-}$ & & \\
\hline relative weight $\%$ & $\stackrel{\circ}{\circ}$ & $\begin{array}{l}\text { 웅 } \\
0\end{array}$ & $\begin{array}{l}\infty \\
\infty \\
0 \\
0\end{array}$ & 商 & 㐫 & 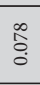 & 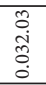 & 苑 & 吕 & $\begin{array}{l}\stackrel{0}{0} \\
\stackrel{0}{0} \\
\stackrel{0}{0}\end{array}$ & 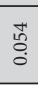 & 只 & $\begin{array}{l}\text { 웅 } \\
0\end{array}$ & శ్ ప్రి & $\stackrel{\sharp}{0}$ & $\begin{array}{l}\text { ô } \\
\stackrel{0}{0}\end{array}$ & 종 & 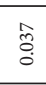 & 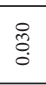 & 荾 & 芦 & & \\
\hline \multirow[t]{2}{*}{ rank } & & & & & & & & & & & & & & & & & & & & & & & \\
\hline & $\infty$ & $=$ & - & $\simeq$ & 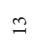 & $m$ & $\stackrel{\infty}{=}$ & $=$ & 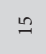 & 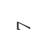 & 6 & 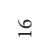 & 임 & $\vec{\lambda}$ & ते & 4 & in & \pm & 2 & + & $a$ & & \\
\hline
\end{tabular}

\footnotetext{
(ㅇ): strong correlation

$\mathrm{O}$ : mid correlation

$\triangle$ : weak correlation
}

FIGURE 7: Incidence matrix table of "fashionable and tasteful” in fuzzy QFD.

lower than $10 \%$. They are quite below the weight values of the top 3 factors, so we can know that interviewees do not care much about whether these 4 factors are present in a minicar. "Hard and burly" is essential to cars, as consumers feel relieved due to the safety level of the car. Moreover, minicars have small sizes and are easy to park, which makes the feelings of "light and lively" and "small and cute" quite natural, but even if we focus on them, customer satisfaction will not be enhanced largely. At the same time, the participants think that the main function of a minicar is to substitute walking, so there is no need to focus on "noble and elegant." Based on the results, the use of the fuzzy Kano model combined with the fuzzy AHP to adjust weights, which is the research method of this study, is suitable for discovering the essential properties of customers' Kansei demands.

In the next stage, we analyze every attractive factor in turn to find out what design elements are effective to some attractive factors. First, we import "fashionable and tasteful" into the incidence matrix of the fuzzy QFD, to assess the detailed design elements of CRs. As can been seen from the results, if we want to meet "fashionable and tasteful" criterion in the design of a minicar, we should consider the elements with the top 4 weights A3, F1, B3, and G2. These elements are the design focus of the matrix deployment. Moreover, it is better to avoid the form features such as E2, G1, C1, and D3 when designing a minicar, as otherwise the products' performance in terms of "fashionable and tasteful" will be reduced. Based on the evaluation results, in terms of the form, consumers think that A3 should be awarded the highest total points, having the weight value of $8.8 \%$. Regarding headlights,
B3 has the highest weight of 7.8\%. For wheel hubs, C3 has the highest weight of $3.6 \%$, for rear view mirrors, D2 has the highest weight of 5.4\%, and, for grille, E1 has the highest weight of $4 \%$. F1 (8.1\%) and G2 (7.4\%) are the top 2 factors for air intakes and fog lamp. The combination of the design features mentioned above is what customers expect from a minicar that is "fashionable and tasteful." Compared to other forms and styles, these factors are more appealing. Therefore, future designers can refer to this result to design the best appearance of a minicar and address closely consumers' demands and aesthetics. Using the process and approach proposed in this study, future designers can also establish communication media with customers to design high-quality products and enhance customer satisfaction.

\section{Conclusion}

Driven by the global competition and customer demands, manufacturers spare no efforts in new product development to maintain competitive advantages. Therefore, the main goal of this study is to build a systematic method to evaluate customers' attractive factors and use them in distinctive new product design. Taking minicars as an example, the article obtains 7 attractive factors using the EGM of experts' opinions, where "fashionable and tasteful" and "appealing and delicate" turn out to have the largest weights. At the same time, they are defined as attractive attributes in the two-dimensional quality classification, which reflects their status as the improvement focus of both experts and customers. Giving priority to them will significantly promote 
customers' satisfaction. "Comfortable and ventilate," "light and lively," "noble and elegant," "small and cute," and "hard and burly" are ranked right after them and they also help to avoid dissatisfaction due to the lack of quality attributes. Further, design methods that improve attractive factors can be obtained using the HoQ matrix, which can provide a reference for enterprises at early stages, so that they can improve product competitiveness while creating market opportunities. In addition, unlike most previous studies using the traditional Miryoku engineering, our proposed integrated method shows good ability to capture effectively and accurately customers' real needs, translating them into attractive product form elements. Most importantly, it has the following advantages:

(i) The EGM extracts customers' attractive factors accurately and rapidly. It also builds the hierarchical relationship between the factors and design elements.

(ii) The fuzzy Kano model combined with the fuzzy AHP weight method explores the relationship between attractive factors and customer satisfaction to determine the development priority of these factors.

(iii) The corresponding hierarchical diagram of these crucial attractive factors is imported into incidence matrices separately, which allows obtaining vital design elements that help designers develop attractive product forms to facilitate sales.

(iv) We adopt fuzzy questionnaires in the experiment using TFNs to express interviewees' subjective evaluation and show what is really in their minds.

There are limitations of this research as follows. First, with the development of science and technology, customers' preferences can be easily influenced by the trends of time. Older products no longer suit new customer needs. Second, this paper does not group interviewees due to the limitations of time and space. Third, although customer preferences are analyzed in this paper, customer orientation should obtain a wider view, such as the consumption ability and consuming behaviors as well as other factors. In the future, customers' attractive factors should be kept updated to meet design trends. Furthermore, we suggest carrying out segmentation studies in different markets using demographic variables such as the gender, age, professional background, and lifestyle.

\section{Conflicts of Interest}

The authors declare that there are no conflicts of interest regarding the publication of this paper.

\section{References}

[1] E. J. Nijssen and R. T. Frambach, "Determinants of the adoption of new product development tools by industrial firms," Industrial Marketing Management, vol. 29, no. 2, pp. 121-131, 2000.

[2] J. C. Narver, S. F. Slater, and B. Tietje, "Creating a market orientation," Journal of Market-Focused Management, vol. 2, no. 3, pp. 241-255, 1998.
[3] D. A. Norman, Emotional Design: Why We Love (or Hate) Everyday Things, Basic Books, New York, NY, USA, 2004.

[4] J. W. Newman, Motivation Research and Marketing Management, Harvard University, Graduate School of Business, Division of Research, Boston, MA, USA, 1957.

[5] P. W. Jordan, Designing Pleasurable Products: An Introduction to the New Human Factors, Taylor and Francis, London, UK, 2000.

[6] R. Jensen, The Dream Society: How the Coming Shift from Information to Imagination Will Transform Your Business, McGrawHill, New York, NY, USA, 1999.

[7] K.-C. Wang, "User-oriented product form design evaluation using integrated kansei engineering scheme," Journal of Convergence Information Technology, vol. 6, no. 6, pp. 420-438, 2011.

[8] M. Nagamachi, "Kansei engineering: a new ergonomic consumer-oriented technology for product development," International Journal of Industrial Ergonomics, vol. 15, no. 1, pp. 3-11, 1995.

[9] C. Tanoue, K. Ishizaka, and M. Nagamachi, "Kansei Engineering: a study on perception of vehicle interior image," International Journal of Industrial Ergonomics, vol. 19, no. 2, pp. 115-128, 1997.

[10] S. Schütte and J. Eklund, "Design of rocker switches for workvehicles-an application of Kansei Engineering," Applied Ergonomics, vol. 36, no. 5, pp. 557-567, 2005.

[11] J. J. Dahlgaard and M. Nagamachi, "Perspectives and the new trend of Kansei/affective engineering," The TQM Journal, vol. 20, no. 4, pp. 290-298, 2008.

[12] J. Vieira, J. M. A. Osório, S. Mouta et al., "Kansei engineering as a tool for the design of in-vehicle rubber keypads," Applied Ergonomics, vol. 61, pp. 1-11, 2017.

[13] M. Ujigawa, "The evolution of preference-based design," Research and Development Institute, vol. 46, pp. 1-10, 2000.

[14] J. Park, J.-H. Kim, E.-J. Park, and S. M. Ham, "Analyzing user experience design of mobile hospital applications using the evaluation grid method," Wireless Personal Communications, vol. 91, no. 4, pp. 1591-1602, 2016.

[15] K. Shen, K. Chen, C. Liang, W. Pu, and M. Ma, "Measuring the functional and usable appeal of crossover B-Car interiors," Human Factors and Ergonomics in Manufacturing \& Service Industries, no. 1, pp. 106-122, 2015.

[16] C.-H. Ho and K.-C. Hou, "Exploring the attractive factors of app icons," KSII Transactions on Internet and Information Systems, vol. 9, no. 6, pp. 2251-2270, 2015.

[17] K.-S. Shen, "Measuring the sociocultural appeal of SNS games in Taiwan," Internet Research, vol. 23, no. 3, pp. 372-392, 2013.

[18] K.-H. Chen, K.-S. Shen, and M.-Y. Ma, "The functional and usable appeal of Facebook SNS games," Internet Research, vol. 22, no. 4, pp. 467-481, 2012.

[19] M.-Y. Ma and L.-T. Y. Tseng, "Applying Miryoku (attractiveness) engineering for evaluation of festival industry," Advances in Information Sciences and Service Sciences, vol. 4, no. 1, pp. 1-9, 2012.

[20] M.-Y. Ma, Y.-C. Chen, and S.-R. Li, "How to build design strategy for attractiveness of new products (DSANP)," Advances in Information Sciences and Service Sciences, vol. 3, no. 11, pp. 1726, 2011.

[21] M. Nagamachi, Y. Okazaki, and M. Ishikawa, "Kansei engineering and application of the rough sets model," Proceedings of the Institution of Mechanical Engineers. Part I: Journal of Systems and Control Engineering, vol. 220, no. 8, pp. 763-768, 2006.

[22] A. Hirohiko, Miryoku Engineering Practice the Procedure of Popular Product, Kaibundo, Tokyo, Japan, 2001. 
[23] G. A. Kelly, The Psychology of Personal Constructs, Norton, New York, NY, USA, 1955.

[24] J. Sanui and M. Inui, "Phenomenological approach to the evaluation of places: a study on the construct system associated with place evaluation," Journal of Architectural Planning and Environmental Engineering, vol. 367, pp. 15-22, 1986.

[25] Y. Akao, Quality Function Deployment: Integrating Customer Requirements into Product Design, Productivity Press, Cambridge, UK, 1990.

[26] J. J. Cristiano, J. K. Liker, and C. C. White III, "Key factors in the successful application of quality function deployment (QFD)," IEEE Transactions on Engineering Management, vol. 48, no. 1, pp. 81-95, 2001.

[27] M. Kowalska, M. Pazdzior, and A. Krzton-Maziopa, "Implementation of QFD method in quality analysis of confectionery products," Journal of Intelligent Manufacturing, vol. 29, pp. 439447, 2018.

[28] L.-X. Wang, "A new look at type-2 fuzzy sets and type-2 fuzzy logic systems," IEEE Transactions on Fuzzy Systems, vol. 25, no. 3, pp. 693-706, 2017.

[29] A. Martí Bigorra and O. Isaksson, "Combining customer needs and the customer's way of using the product to set customerfocused targets in the House of Quality," International Journal of Production Research, vol. 55, no. 8, pp. 2320-2335, 2017.

[30] W. Jia, Z. Liu, Z. Lin, C. Qiu, and J. Tan, "Quantification for the importance degree of engineering characteristics with a multilevel hierarchical structure in QFD," International Journal of Production Research, vol. 54, no. 6, pp. 1627-1649, 2015.

[31] H. Raharjo, M. Xie, and A. C. Brombacher, "A systematic methodology to deal with the dynamics of customer needs in Quality Function Deployment," Expert Systems with Applications, vol. 38, no. 4, pp. 3653-3662, 2011.

[32] L.-K. Chan and M.-L. Wu, "Quality function deployment: a literature review," European Journal of Operational Research, vol. 143, no. 3, pp. 463-497, 2002.

[33] L. R. Guinta and N. C. Praizler, The QFD Book: The Team Approach to Solving Problems and Satisfying Customers through Quality Function Deployment, Amacom, New York, NY, USA, 1993.

[34] J. R. Hauser and D. Clausing, "The house of quality," Harvard Business Review, vol. 66, no. 3, pp. 63-73, 1988.

[35] L. P. Khoo and N. C. Hot, "Framework of a fuzzy quality function deployment system," International Journal of Production Research, vol. 34, no. 2, pp. 299-311, 1996.

[36] L.-K. Chan and M.-L. Wu, "A systematic approach to quality function deployment with a full illustrative example," Omega , vol. 33, no. 2, pp. 119-139, 2005.

[37] Q. Wu, "Fuzzy measurable house of quality and quality function deployment for fuzzy regression estimation problem," Expert Systems with Applications, vol. 38, no. 12, pp. 14398-14406, 2011.

[38] S. Zaim, M. Sevkli, H. Camgöz-Akdağ, O. F. Demirel, A. Yesim Yayla, and D. Delen, "Use of ANP weighted crisp and fuzzy QFD for product development," Expert Systems with Applications, vol. 41, no. 9, pp. 4464-4474, 2014.

[39] L.-Z. Lin, H.-R. Yeh, and M.-C. Wang, "Integration of Kano's model into FQFD for Taiwanese Ban-Doh banquet culture," Tourism Management, vol. 46, pp. 245-262, 2015.

[40] S. Vinodh, K. J. Manjunatheshwara, S. Karthik Sundaram, and V. Kirthivasan, "Application of fuzzy quality function deployment for sustainable design of consumer electronics products: a case study," Clean Technologies and Environmental Policy, vol. 19, no. 4, pp. 1021-1030, 2017.
[41] N. Kano, N. Seraku, F. Takahashi, and S. Tsuji, "Attractive quality and must-be quality," Journal of The Japanese Society for Quality Control, vol. 14, no. 2, pp. 147-156, 1984.

[42] C. Berger, R. Blauth, D. Boger et al., "Kano's methods for understanding customer-defined quality," The Center for Quality of Management Journal, vol. 2, no. 4, pp. 3-36, 1993.

[43] H. C. Yadav, R. Jain, A. R. Singh, and P. K. Mishra, "Kano integrated robust design approach for aesthetical product design: a case study of a car profile," Journal of Intelligent Manufacturing, vol. 28, no. 7, pp. 1709-1727, 2017.

[44] N. Velikova, L. Slevitch, and K. Mathe-Soulek, "Application of Kano model to identification of wine festival satisfaction drivers," International Journal of Contemporary Hospitality Management, vol. 29, no. 10, pp. 2708-2726, 2017.

[45] P. Ji, J. Jin, T. Wang, and Y. Chen, "Quantification and integration of Kano's model into QFD for optimising product design," International Journal of Production Research, vol. 52, no. 21, pp. 6335-6348, 2014.

[46] C.-H. Wang and O.-Z. Hsueh, "A novel approach to incorporate customer preference and perception into product configuration: a case study on smart pads," Computer Standards \& Interfaces, vol. 35, no. 5, pp. 549-556, 2013.

[47] M. Hartono and T. K. Chuan, "How the Kano model contributes to Kansei engineering in services," Ergonomics, vol. 54, no. 11, pp. 987-1004, 2011.

[48] C. Llinares and A. F. Page, "Kano's model in Kansei Engineering to evaluate subjective real estate consumer preferences," International Journal of Industrial Ergonomics, vol. 41, no. 3, pp. 233246, 2011.

[49] A. M. M. Sharif Ullah and J. Tamaki, "Analysis of Kano-modelbased customer needs for product development," Systems Engineering, vol. 14, no. 2, pp. 154-172, 2011.

[50] C. C. Chen and M. C. Chuang, "Integrating the Kano model into a robust design approach to enhance customer satisfaction with product design," International Journal of Production Economics, vol. 114, no. 2, pp. 667-681, 2008.

[51] Y.-C. Lee and S.-Y. Huang, "A new fuzzy concept approach for Kano's model," Expert Systems with Applications, vol. 36, no. 3, pp. 4479-4484, 2009.

[52] H. C. Yadav, R. Jain, S. Shukla, S. Avikal, and P. K. Mishra, "Prioritization of aesthetic attributes of car profile," International Journal of Industrial Ergonomics, vol. 43, no. 4, pp. 296-303, 2013.

[53] C.-H. Wang, "Incorporating customer satisfaction into the decision-making process of product configuration: a fuzzy kano perspective," International Journal of Production Research, vol. 51, no. 22, pp. 6651-6662, 2013.

[54] C.-H. Wang and J. Wang, "Combining fuzzy AHP and fuzzy Kano to optimize product varieties for smart cameras: a zeroone integer programming perspective," Applied Soft Computing, vol. 22, pp. 410-416, 2014.

[55] M. G. Violante and E. Vezzetti, "Kano qualitative vs quantitative approaches: an assessment framework for products attributes analysis," Computers in Industry, vol. 86, pp. 15-25, 2017.

[56] T. L. Saaty, The Analysis Hierarchy Process: Planning, Priority Setting, Resource Allocation, McGraw-Hill, New York, NY, USA, 1980.

[57] G.-N. Zhu, J. Hu, J. Qi, C.-C. Gu, and Y.-H. Peng, "An integrated AHP and VIKOR for design concept evaluation based on rough number," Advanced Engineering Informatics, vol. 29, no. 3, pp. 408-418, 2015. 
[58] Y. Sato, K. H. Tan, and Y. K. Tse, "An integrated marginal analysis approach for build-to-order products," International Journal of Production Economics, vol. 170, pp. 422-428, 2015.

[59] J. Ooi, M. A. B. Promentilla, R. R. Tan, D. K. S. Ng, and N. G. Chemmangattuvalappil, "A systematic methodology for multiobjective molecular design via analytic hierarchy process," Process Safety and Environmental Protection, vol. 111, pp. 663677, 2017.

[60] L. A. Zadeh, "Fuzzy sets," Information and Computation, vol. 8, pp. 338-353, 1965.

[61] P. J. M. Laarhoven and W. Pedrycz, "A fuzzy extension of Saaty's priority theory," Fuzzy Sets and Systems, vol. 11, no. 1-3, pp. 229241, 1983.

[62] J. J. Buckley, "Fuzzy hierarchical analysis," Fuzzy Sets and Systems, vol. 17, no. 3, pp. 233-247, 1985.

[63] S. E. Alptekin, "A fuzzy decision support system for digital camera selection based on user preferences," Expert Systems with Applications, vol. 39, no. 3, pp. 3037-3047, 2012.

[64] J. Cho and J. Lee, "Development of a new technology product evaluation model for assessing commercialization opportunities using Delphi method and fuzzy AHP approach," Expert Systems with Applications, vol. 40, no. 13, pp. 5314-5330, 2013.

[65] T.-M. Yeh, F.-Y. Pai, and C.-W. Liao, "Using a hybrid MCDM methodology to identify critical factors in new product development," Neural Computing and Applications, vol. 24, no. 3-4, pp. 957-971, 2014.

[66] M. Sabaghi, C. Mascle, P. Baptiste, and R. Rostamzadeh, "Sustainability assessment using fuzzy-inference technique (SAFT): a methodology toward green products," Expert Systems with Applications, vol. 56, pp. 69-79, 2016.

[67] M.-D. Shieh, Y. Li, and C.-C. Yang, "Product form design model based on multiobjective optimization and multicriteria decision-making," Mathematical Problems in Engineering, vol. 2017, Article ID 5187521, 15 pages, 2017.

[68] K. Matzler and H. H. Hinterhuber, "How to make product development projects more successful by integrating Kano's model of customer satisfaction into quality function deployment," Technovation, vol. 18, no. 1, pp. 25-38, 1998.

[69] CQM, "A special issue on Kanos methods for understanding customer defined quality," Center For Quality Management Journal, vol. 2, no. 4, pp. 3-35, 1993.

[70] L. A. Zadeh, "The concept of a linguistic variable and its application to approximate reasoning I," Information Sciences, vol. 8, no. 3, pp. 199-249, 1975.

[71] J.-Y. Teng and G.-H. Tzeng, "Fuzzy multicriteria ranking of urban transportation investment alternatives," Transportation Planning and Technology, vol. 20, no. 1, pp. 15-31, 1996.

[72] K. C. Tan and T. A. Pawitra, "Integrating SERVQUAL and Kano's model into QFD for service excellence development," Managing Service Quality, vol. 11, no. 6, pp. 418-430, 2001.

[73] L. Cohen, Quality Function Deployment: How to Make QFD Work for You, Addison Wesley, Massachusetts, MA, USA, 1995. 


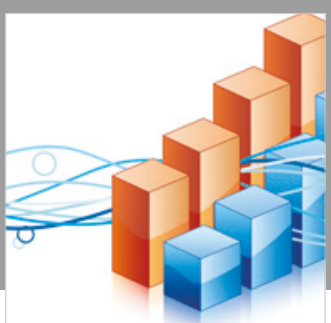

Advances in

Operations Research

\section{-n-m}
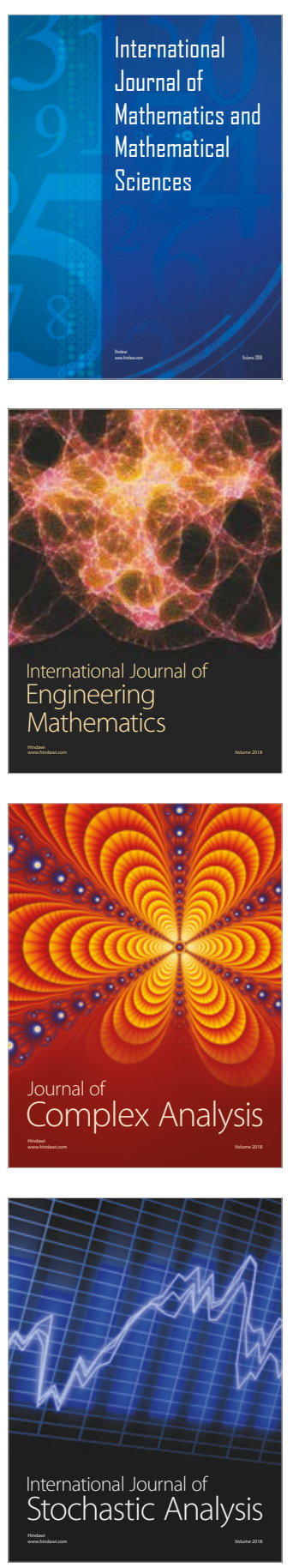
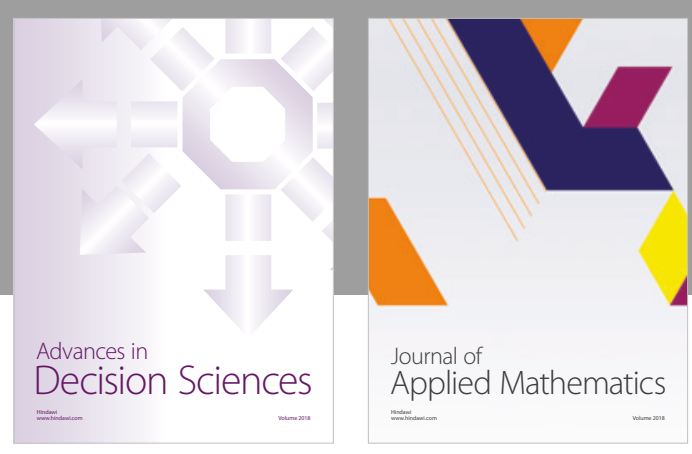

Journal of

Applied Mathematics
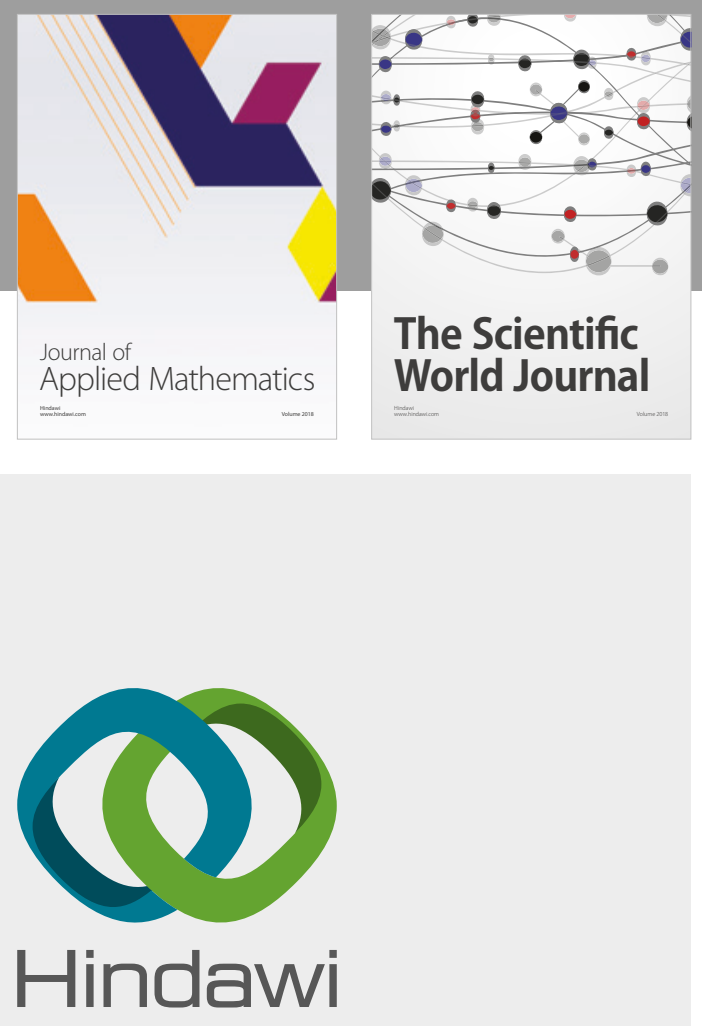

Submit your manuscripts at

www.hindawi.com

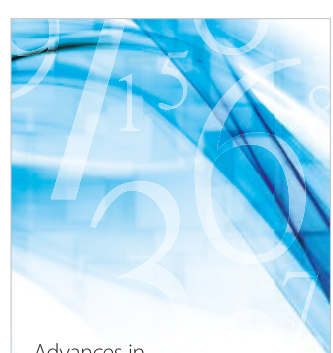

Advances in
Numerical Analysis
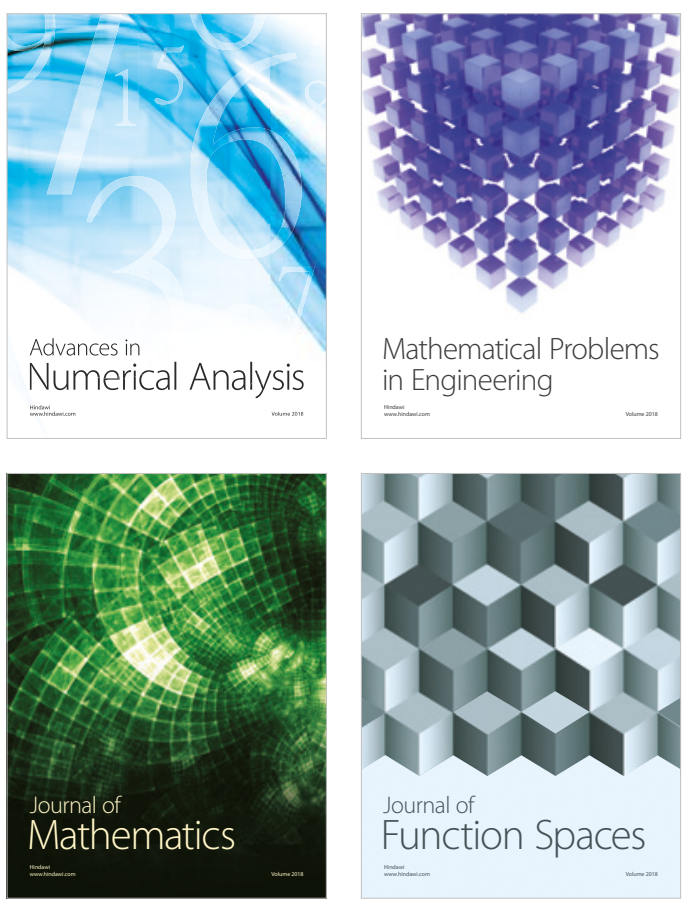

Mathematical Problems in Engineering

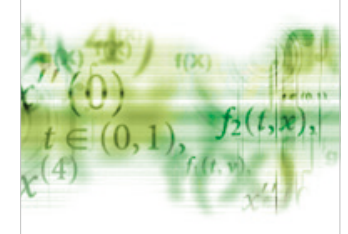

International Journal of

Differential Equations

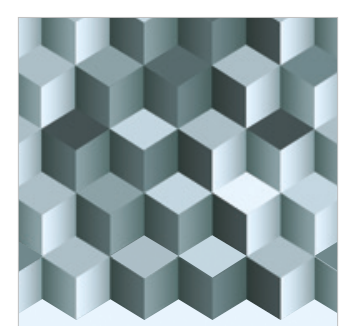

Journal of

Function Spaces

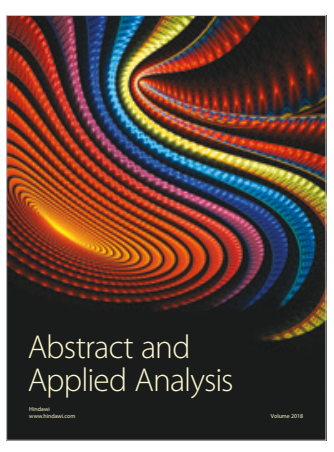

The Scientific

World Journal

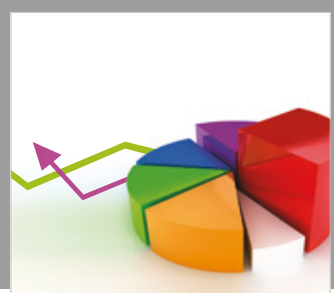

Journal of

Probability and Statistics
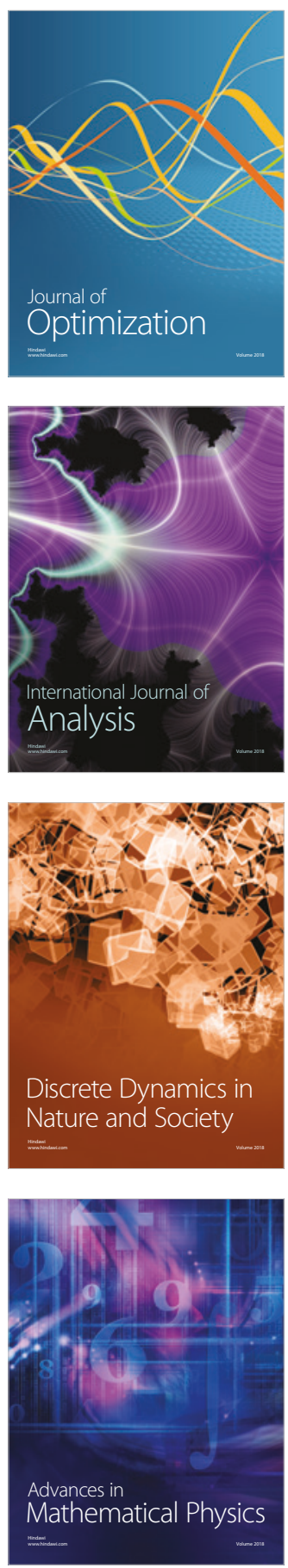